"Mircea cel Batran" Naval Academy Scientific Bulletin, Volume XX - 2017 - Issue 1

The journal is indexed in: PROQUEST I DOAJ / Crossref / EBSCOhost / INDEX COPERNICUS / DRJI / OAJI I

JOURNAL INDEX / I2OR / SCIENCE LIBRARY INDEX / Google Scholar / Academic Keys/ ROAD Open Access I Academic Resources / Scientific Indexing Services / SCIPIO / JIFACTOR

\title{
THE PROCESSING ELEMENTS BY DRAWING
}

\section{Aurelia CHIOIBAS ${ }^{1}$}

${ }^{1}$ Lecturer Ph. D. Eng. Dep. IMAN, Naval Academy “Mircea cel Batran”, Str. Fulgerului nr. 1, chioibasaura@yahoo.com

Abstract: This paper is an overview of the technological system of processing and factors that characterize the drawing, because the piece is the result of interactions between all of them.

Key words: press, blank, die, operator, drawing process

\subsection{The technological system components} by drawing processing

The drawing piece result from interactions between the technological system components by drawing processing which is comprised of: press, blank die, operator and subsystems supply blanks and evacuation parts and wastes (Fig. 1 [1]).

The pieces are characterized by size and shape. If cylindrical parts, depending on the ratio between height and diameter are distinguished small parts, medium and large. After the form piece can be of revolution (without flange, with wide or narrow flange), box (with or without flange) or asymmetric.

The blank is converted in part due to the deformations to which it is subjected in accordance with the set processing (Fig. 3 [1]).

In Tables 1.1 [3] and 1.2 [3] are the types of ferrous and non ferrous materials used in these processing.

Tab. 1.1. Ferrous materials used in drawing process

\begin{tabular}{|l|l|l|}
\hline \multicolumn{1}{|c|}{ The blank name } & \multicolumn{1}{|c|}{ The material } & $\begin{array}{c}\text { The sheet } \\
\text { thickness } \mathrm{g}[\mathrm{mm}]\end{array}$ \\
\hline Tinned sheet & The pickled sheet & $\mathrm{g}=0,22 \div 0,6$ \\
\hline $\begin{array}{l}\text { Narrow strip cold-rolled } \\
\text { carbon steel }\end{array}$ & OL 32 & $\mathrm{g}=0,3 \div 3,5$ \\
\hline Hot rolled strip & OL 50; OLC 60 & $\mathrm{g}=2 \div 5$ \\
\hline $\begin{array}{l}\text { Wide strip of hot rolled steel } \\
\text { in coils }\end{array}$ & $\begin{array}{l}\text { OL 50; OLC 60, drawing } \\
\text { steel }\end{array}$ & $\mathrm{g}=3 \div 12$ \\
\hline Black sheet & OL 32, OL 34 & $\mathrm{g}=0,25 \div 1$ \\
\hline Galvanized sheet & OL 32, OL 34 & $\mathrm{g}=0,3 \div 4$ \\
\hline Cold rolled steel strips & Steel for springs & $\mathrm{g}=0,2 \div 2,2$ \\
\hline Wide strip cold-rolled steel & Carbon steel & $\mathrm{g}=0,3 \div 3$ \\
\hline Sheets and tapes for drawing & Carbon steel & $\mathrm{g}=0,5 \div 2$ \\
\hline $\begin{array}{l}\text { Thin sheet metal of cold } \\
\text { rolled steel }\end{array}$ & Carbon steel & $\mathrm{g}=0,4 \div 3,5$ \\
\hline
\end{tabular}


"Mircea cel Batran" Naval Academy Scientific Bulletin, Volume XX - 2017 - Issue 1 The journal is indexed in: PROQUEST I DOAJ / Crossref / EBSCOhost / INDEX COPERNICUS / DRJI / OAJI I JOURNAL INDEX I I2OR / SCIENCE LIBRARY INDEX / Google Scholar / Academic Keys/ ROAD Open Access I Academic Resources / Scientific Indexing Services / SCIPIO I JIFACTOR

Tab. 1.2. Metals and nonferrous alloys used in drawing

\begin{tabular}{|l|l|l|}
\hline \multicolumn{1}{|c|}{ The blank name } & \multicolumn{1}{|c|}{ The material } & The sheet thickness $\mathrm{g}$ [mm] \\
\hline Copper zinc alloys sheets & $\begin{array}{l}\text { CuZn 10; CuZn 15; CuZn 20; } \\
\text { CuZn30; CuZn31Si;CuZn 36; }\end{array}$ & $\mathrm{g}=0,5 \div 5$ \\
\hline Copper zinc alloy tapes & $\begin{array}{l}\text { CuZn 10; CuZn 15; CuZn 20; } \\
\text { CuZn 30; CuZn 36; }\end{array}$ & $\mathrm{g}=0,1 \div 2$ \\
\hline Copper sheets & Cu 99,97; Cu 99,95; Cu 99,9; & $\mathrm{g}=0,5 \div 5$ \\
\hline Copper tapes & Cu 99,97; Cu 99,95; Cu 99,9; & $\mathrm{g}=0,1 \div 2$ \\
\hline Aluminum sheets & $\begin{array}{l}\text { Al 99,8; Al 99,7; Al 99,5; Al } \\
99,3 ; \text { Al 99,0; }\end{array}$ & $\mathrm{g}=0,3 \div 5$ \\
\hline $\begin{array}{l}\text { Zinc and aluminum alloys } \\
\text { sheets }\end{array}$ & $\begin{array}{l}\text { Zn 99,99; Zn 99,98; Zn 98,6; Zn } \\
98,5 ;\end{array}$ & $\mathrm{g}=0,3 \div 6$ \\
\hline $\begin{array}{l}\text { Argentan sheets and tapes } \\
\text { (alloy Cu-Ni-Zn) }\end{array}$ & Usually CuNi18Zn27; & $\begin{array}{l}\text { sheets: } \mathrm{g}=0,5 \div 5 ; \\
\text { tapes: } \mathrm{g}=0,1 \div 2,5 ;\end{array}$ \\
\hline Copper disks & Cu 99,97; Cu 99,95; Cu 99,9; & $\mathrm{D}=200 \div 650 ;$ \\
& Al 99,7; Al 99,5; Al 99,0; & $\mathrm{g}=0,8 ; 1 ; 1,5 ;$ \\
\hline $\begin{array}{l}\text { Zinc-copper alloy disks } \\
\text { tapes (Cu-Zn alloys) }\end{array}$ & CuZn63; & $\mathrm{D}=200 \div 650 ;$ \\
$\mathrm{gluminum}$ tapes & $\mathrm{g}=0,8 ; 1 ; 1,5 ;$ \\
\hline
\end{tabular}

The blanks may be individual or tape (Fig. 3) [1].The blanks may take the form of individual plane (Fig. 4 [2], Fig. 5 [4], Fig. 6 [4], Fig. 7 [4]) or concave (Fig. 4d, e, f). May result parts of revolution or boxes with or without flange from the blanks concave. From the individual disc-shaped blanks may be obtained flanged cylindrical parts (Fig. 4b) or without flange (Fig. 4), truncated cone
(Fig. 4c) or high squares with large rounding radius. If piece of revolution will be applied cutting edge operation (because after cupping result with festoons), is recommended the use a blank square with the corners cut. The sides of the square are parallel and perpendicular to the fiber sheet so that the disc area to be equal to the square without corners (Fig. 5). 
"Mircea cel Batran" Naval Academy Scientific Bulletin, Volume XX - 2017 - Issue 1

The journal is indexed in: PROQUEST I DOAJ / Crossref / EBSCOhost / INDEX COPERNICUS / DRJI / OAJI I JOURNAL INDEX / I2OR / SCIENCE LIBRARY INDEX / Google Scholar / Academic Keys/ ROAD Open Access I Academic Resources / Scientific Indexing Services / SCIPIO / JIFACTOR

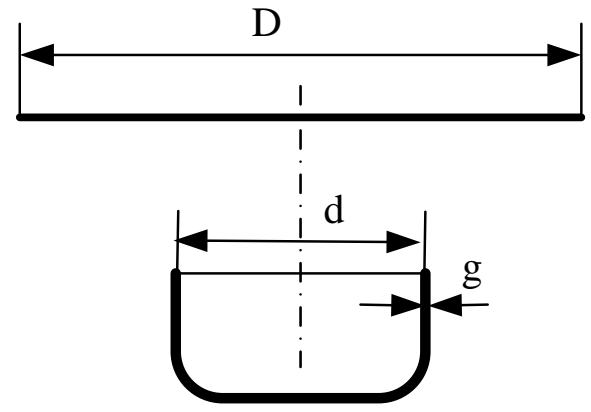

$\mathrm{a}$
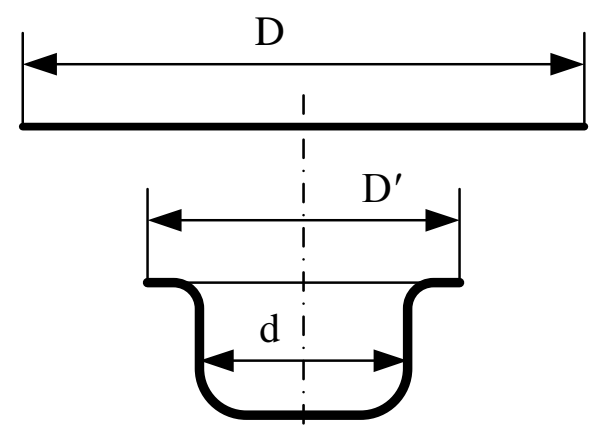

$\mathrm{b}$
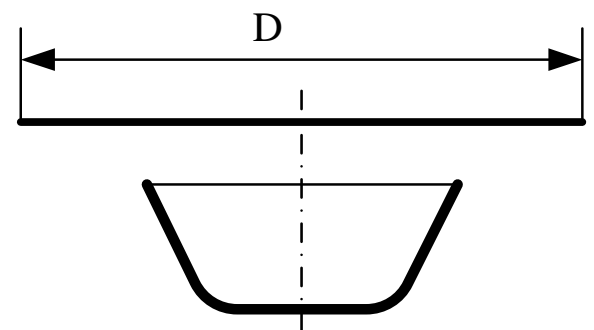

C

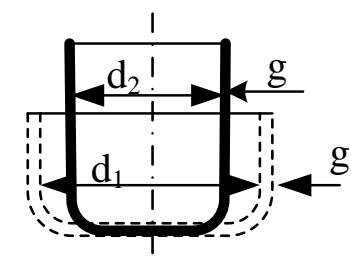

d
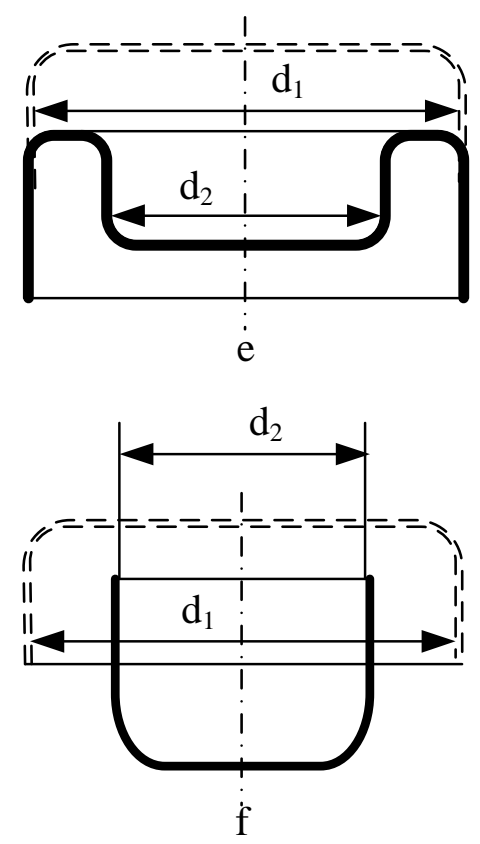

Fig. 4. The blank shape

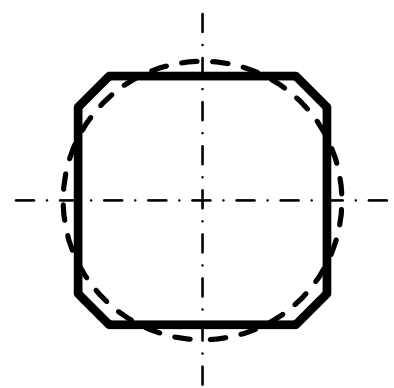

Fig. 5. The blank square shape with cut corners 
"Mircea cel Batran" Naval Academy Scientific Bulletin, Volume XX - 2017 - Issue 1 The journal is indexed in: PROQUEST I DOAJ / Crossref / EBSCOhost / INDEX COPERNICUS / DRJI / OAJI I JOURNAL INDEX / I2OR / SCIENCE LIBRARY INDEX / Google Scholar / Academic Keys/ ROAD Open Access I Academic Resources / Scientific Indexing Services / SCIPIO / JIFACTOR

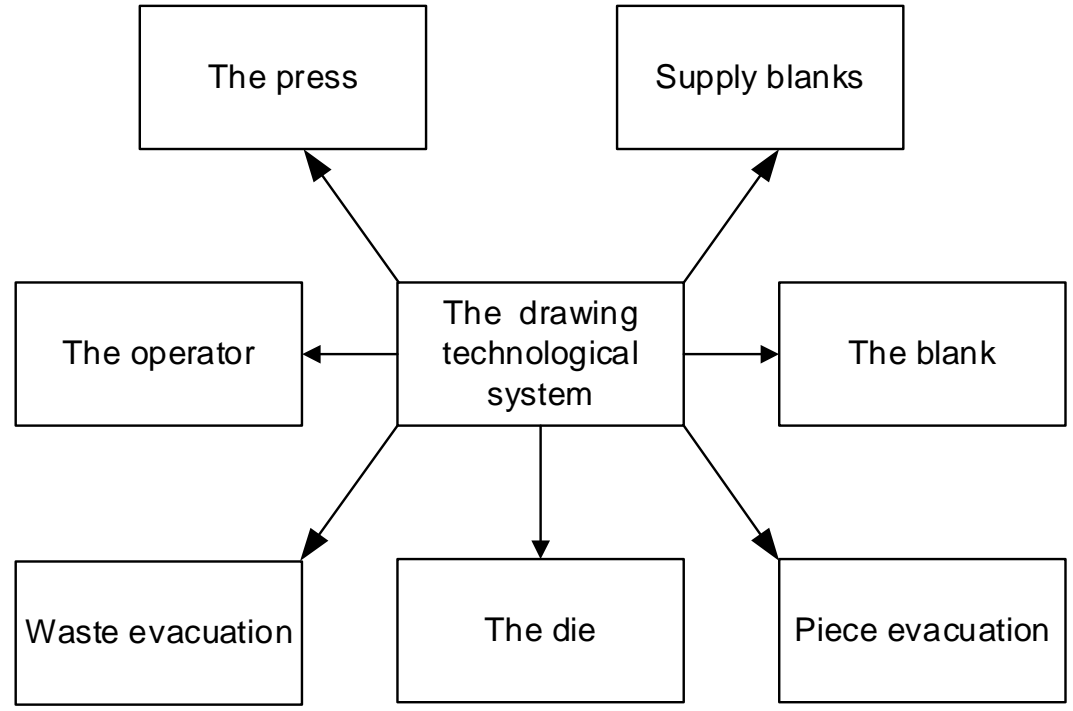

Fig. 1. The drawing technological system

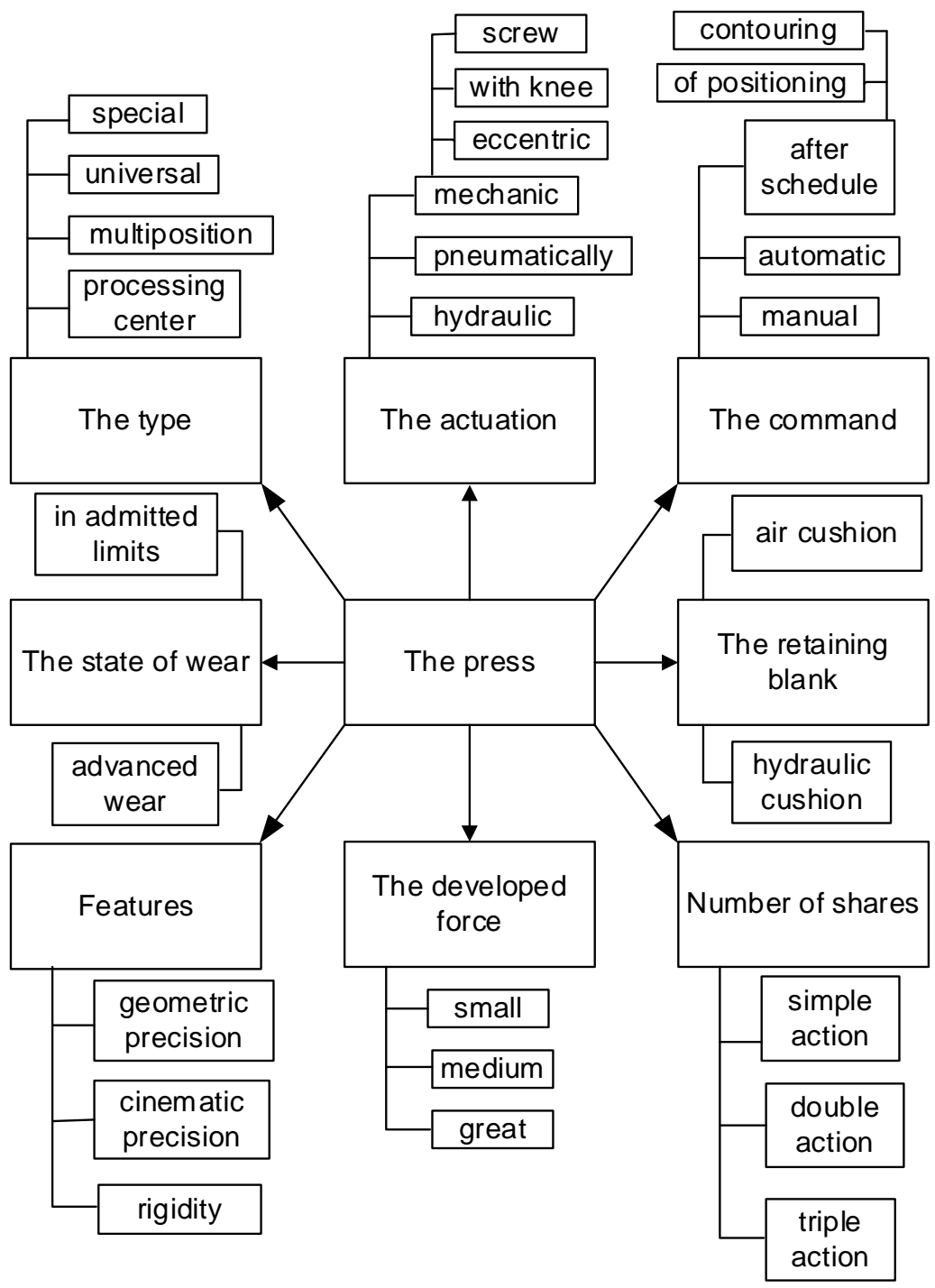

Fig. 2 The subsystem "The press" 
"Mircea cel Batran" Naval Academy Scientific Bulletin, Volume XX - 2017 - Issue 1

The journal is indexed in: PROQUEST I DOAJ / Crossref / EBSCOhost / INDEX COPERNICUS / DRJI / OAJI I JOURNAL INDEX / I2OR / SCIENCE LIBRARY INDEX / Google Scholar / Academic Keys/ ROAD Open Access I Academic Resources / Scientific Indexing Services / SCIPIO / JIFACTOR

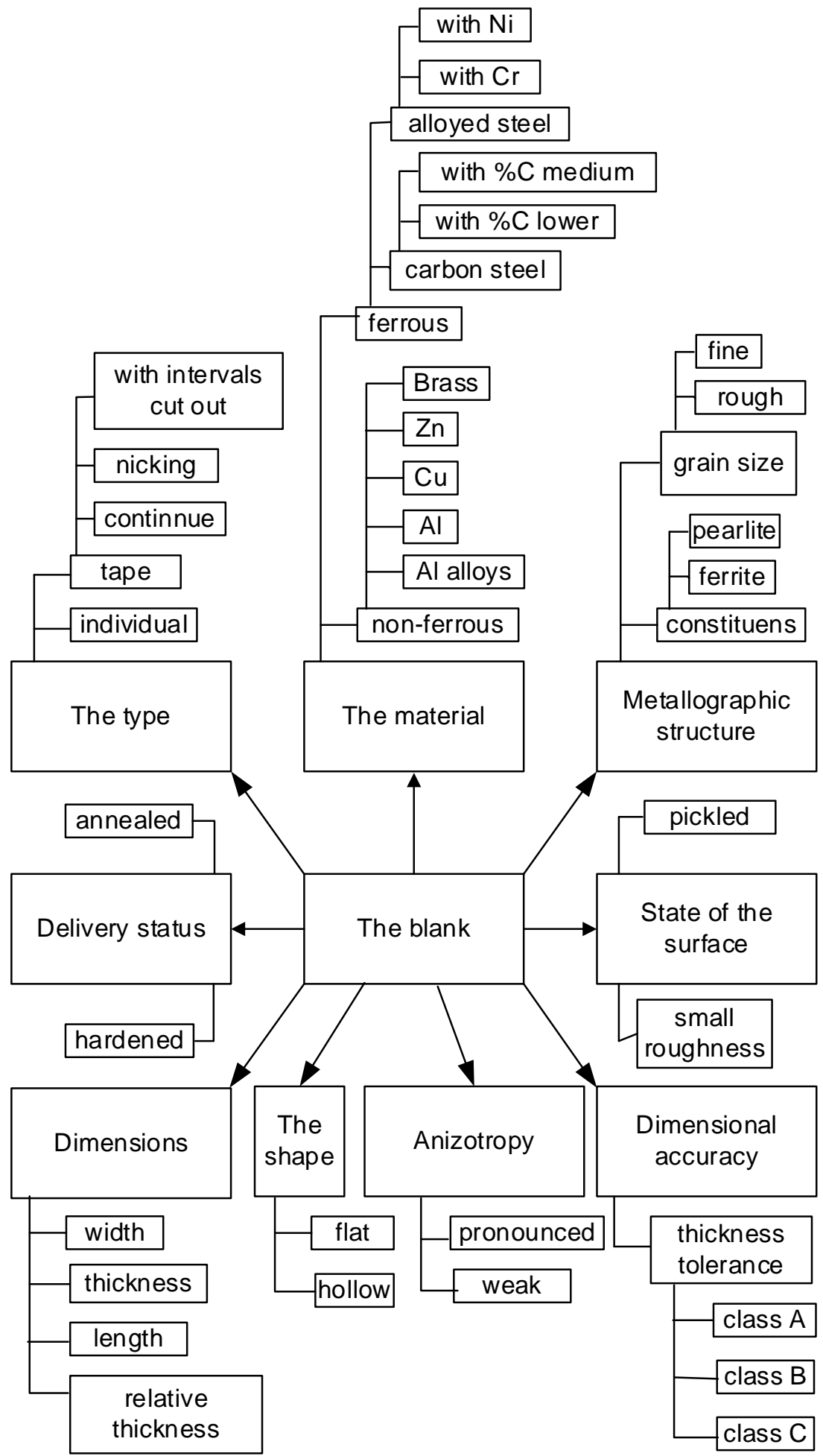

Fig. 3. The Subsystem "The blank"

From plane blanks whose form as a result of 
"Mircea cel Batran" Naval Academy Scientific Bulletin, Volume XX - 2017 - Issue 1

The journal is indexed in: PROQUEST I DOAJ / Crossref / EBSCOhost / INDEX COPERNICUS / DRJI / OAJI I

JOURNAL INDEX / I2OR / SCIENCE LIBRARY INDEX / Google Scholar / Academic Keys/ ROAD Open Access I Academic Resources / Scientific Indexing Services / SCIPIO / JIFACTOR

the boxes are obtained (parallelepipedals pieces). Thus, for high rectangular boxes that have large rounding radius corners, the blank is elliptical. In the case of parallelepipedal pieces shorter or medium with high connection radii of the corners, the shape of the blanks is shown in Fig. 6. Areas with hatching width " $h_{t}$ " are removed from the unfolded walls (width "l") because some of the material moving walls corners drawing box. "R" is the radius of the corner blank, deriving from the unfolded corner of the box. " $\mathrm{R}_{\mathrm{a}}$ " represents correction value "R" and is necessary to compensate for the material moving toward the side walls. " $R_{t}$ " is the radius of the corner with sides, to ensure a smoother contour. The " $r$ " was noted the radius of corner of the box. To obtain shorter parallelepipedal parts with small corner radii of connection, the form of the blank shown in Fig 7. In this case too, if applied to the edges of the cutting operation, the blank is shaped like a square or rectangle with corners cut. This choice is determined by simplifying construction of the stamping die used to cut the blank.

In case of drawing successive band using continuous band or without cuts (Fig. 8 [5]), increase (Fig. 9 [5]) with punching intermediate areas (Fig. 10 [5]) or perforation intermediate areas and cutting edge (Fig. 11 [5]). We used the following notation: $D_{s}$ is the diameter of the blank, $a_{1}$ is the intermediate zone, $a_{2}$ is the side decks, $p$ is the step, $A$ is the width of the deck, $B$ is the width of the tape.

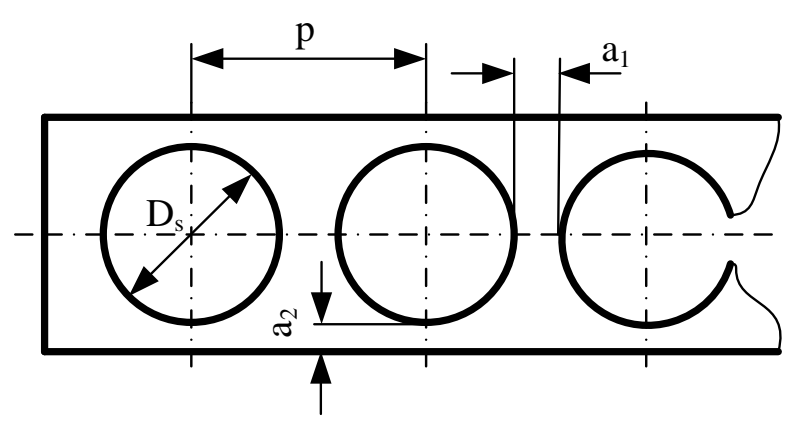

Fig. 8. The blank shape for drawing successive band without cut

\section{DOI: 10.}

(C) 2017. Th 5 work is licensed under the Creative Commons Attribution-Noncommercial-Share Alike 4.0 License.

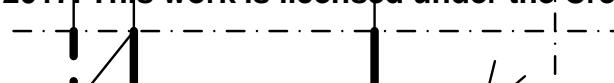




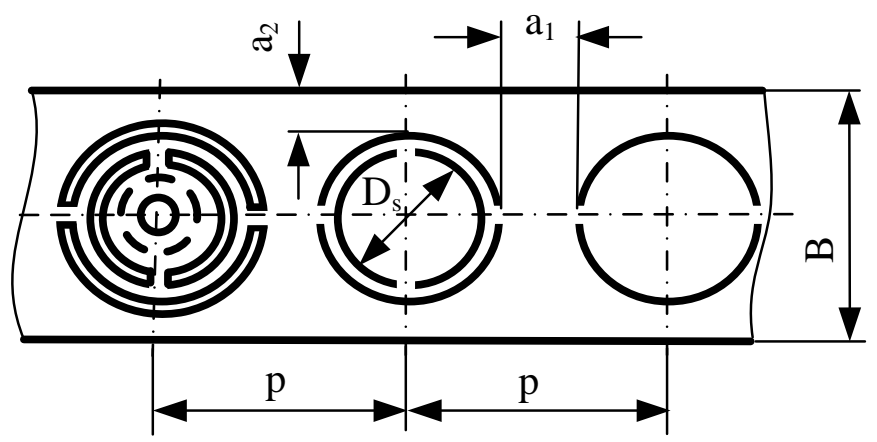

Fig. 9. The nicking strip used to the successive drawing

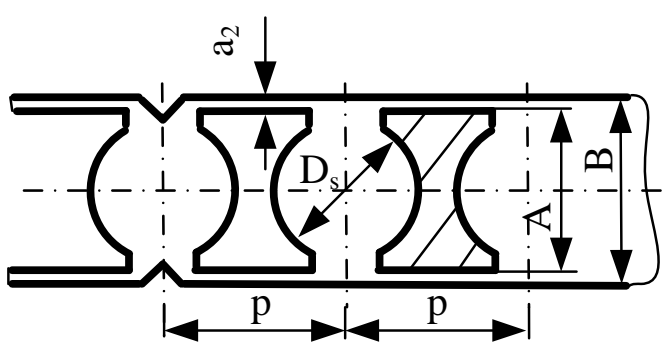

Fig. 10. Punching of the intermediate areas

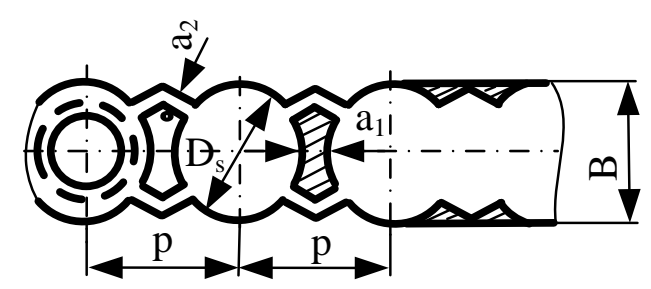

Fig. 11. Punching of the intermediate areas and cutting edges 
"Mircea cel Batran" Naval Academy Scientific Bulletin, Volume XX - 2017 - Issue 1 The journal is indexed in: PROQUEST I DOAJ / Crossref / EBSCOhost / INDEX COPERNICUS / DRJI / OAJI I JOURNAL INDEX / I2OR / SCIENCE LIBRARY INDEX / Google Scholar / Academic Keys/ ROAD Open Access I Academic Resources / Scientific Indexing Services / SCIPIO / JIFACTOR

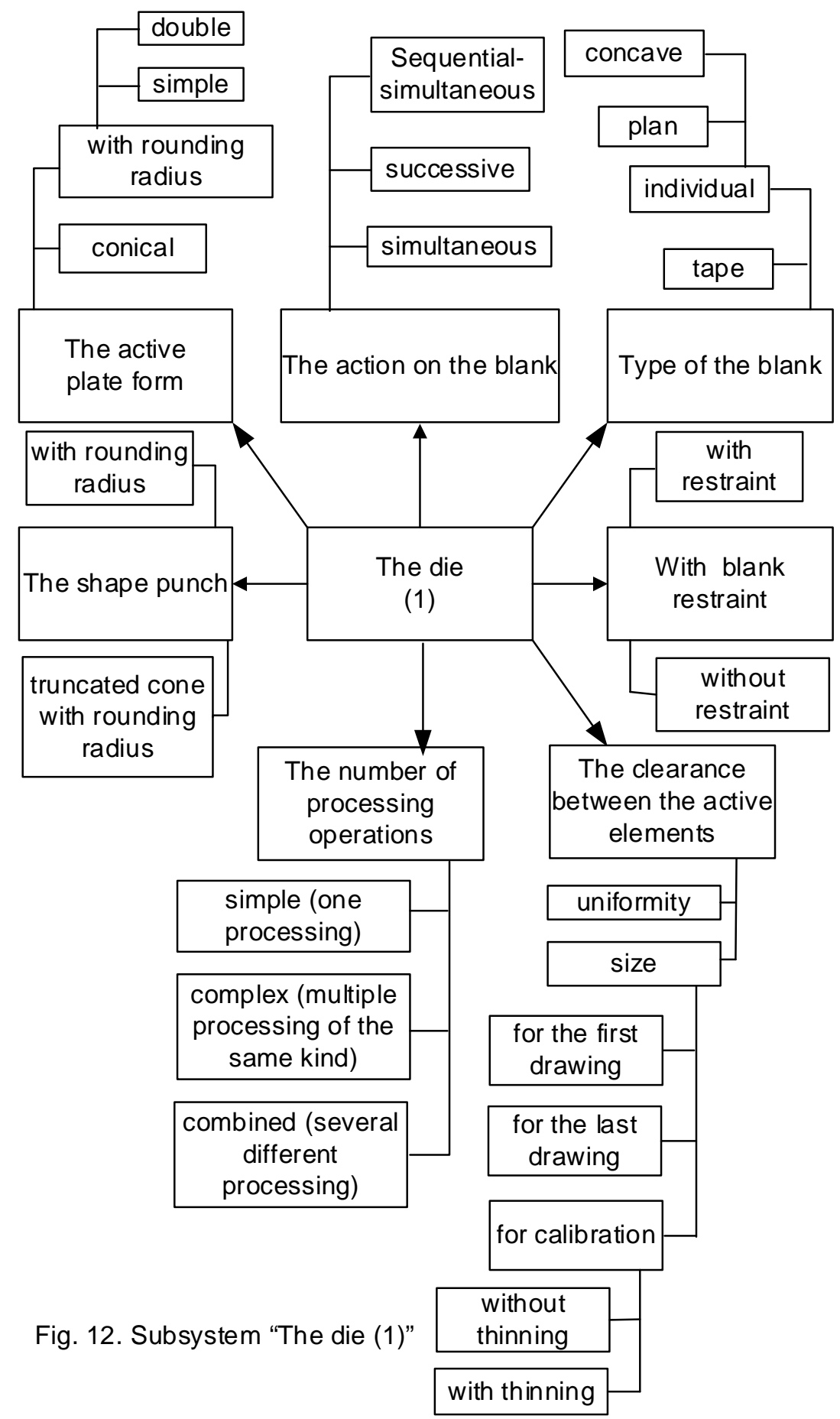


"Mircea cel Batran" Naval Academy Scientific Bulletin, Volume XX - 2017 - Issue 1

The journal is indexed in: PROQUEST I DOAJ / Crossref / EBSCOhost / INDEX COPERNICUS / DRJI / OAJI I JOURNAL INDEX / I2OR / SCIENCE LIBRARY INDEX / Google Scholar / Academic Keys/ ROAD Open Access I Academic Resources / Scientific Indexing Services / SCIPIO / JIFACTOR

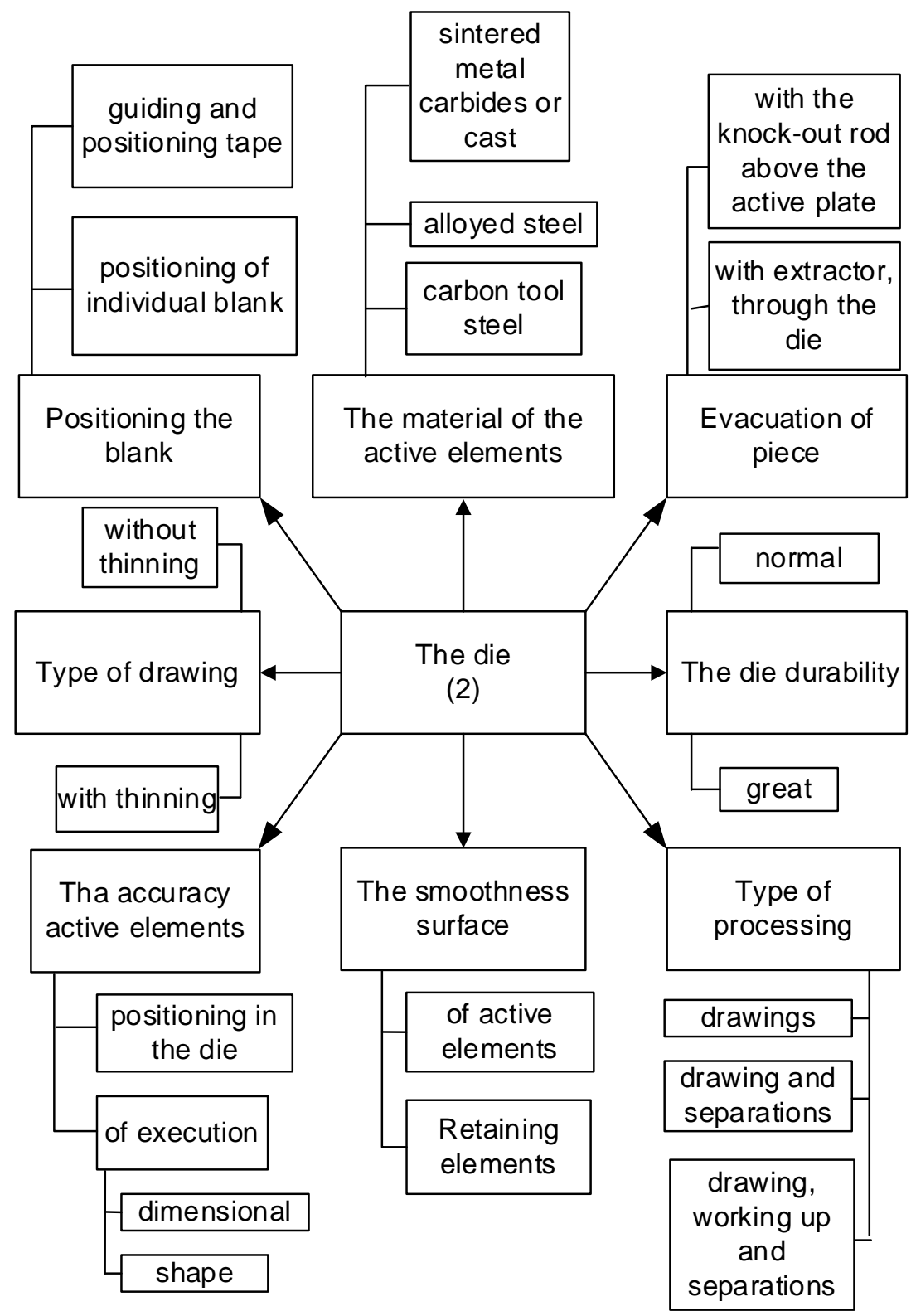

Fig. 12. Subsistemul "Matrita (2)"

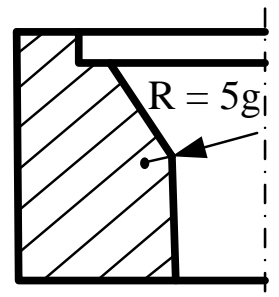

Fig. 13. The active drawing board with a part release conical
The die receives energy from the press and apply the blank, so as to produce deformation thereof in the manufacture them according to the drawing (Fig. 12a and b [1]), from point of view of shape and size. The die is composed of plate drawing and punch. If aims at obtaining a quality pieces, then upper package contains (besides punch) and retaining ring.

Active board can be connected to the radius $r_{p l}$ (Fig. 16 [2]), conical (Fig. 13 [2]), evolvent (Fig. 14 [2]) or stepped (Fig. 15 [2]). 
"Mircea cel Batran" Naval Academy Scientific Bulletin, Volume XX - 2017 - Issue 1

The journal is indexed in: PROQUEST / DOAJ / Crossref / EBSCOhost / INDEX COPERNICUS / DRJI / OAJI I JOURNAL INDEX I I2OR / SCIENCE LIBRARY INDEX / Google Scholar / Academic Keys/ ROAD Open Access I Academic Resources / Scientific Indexing Services / SCIPIO / JIFACTOR

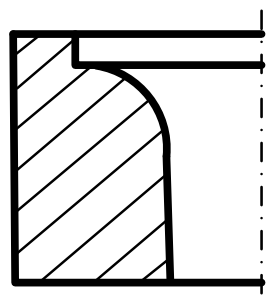

Fig. 14. The active drawing board with a part release evolvent

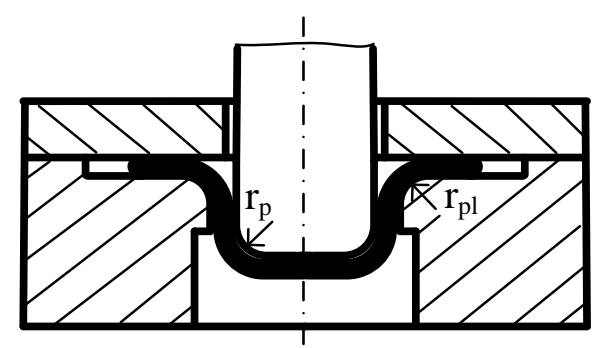

Fig. 16. The active elements of die drawing with rounded edges

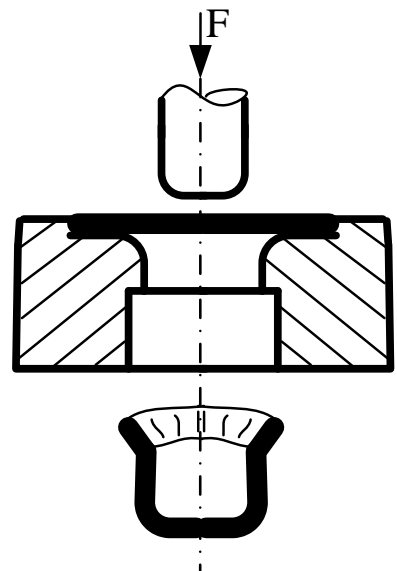

Fig. 18. The drwaing scheme without restrain

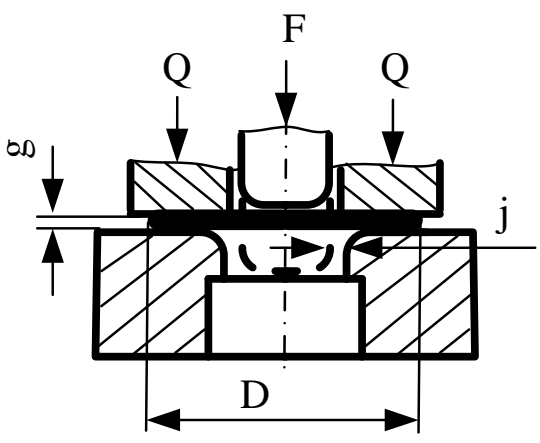

Fig. 21. The elastic retention of the blank

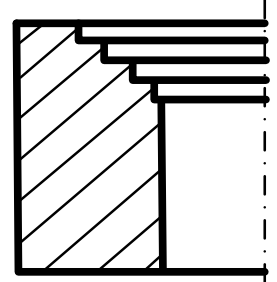

Fig. 15. The active drawing board with a part release in steps

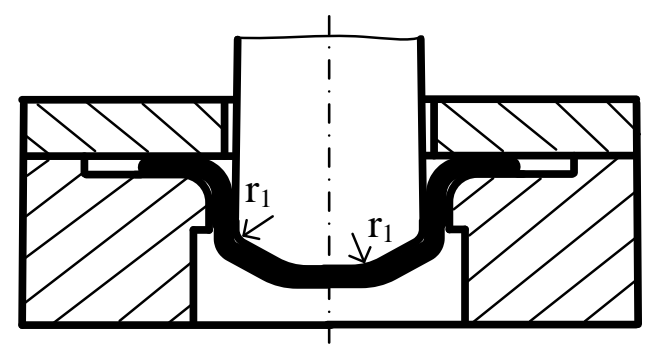

Fig. 17. The drawing die with tronconic punch

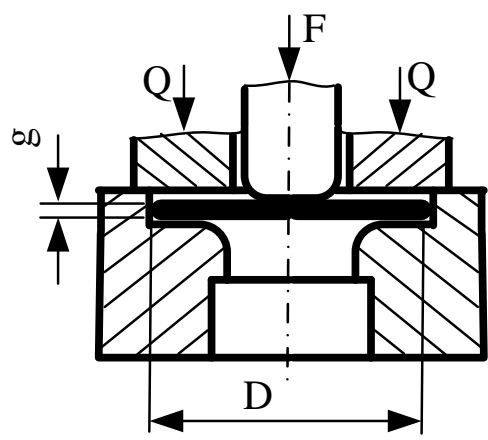

Fig. 19. The rigid retention of the blank

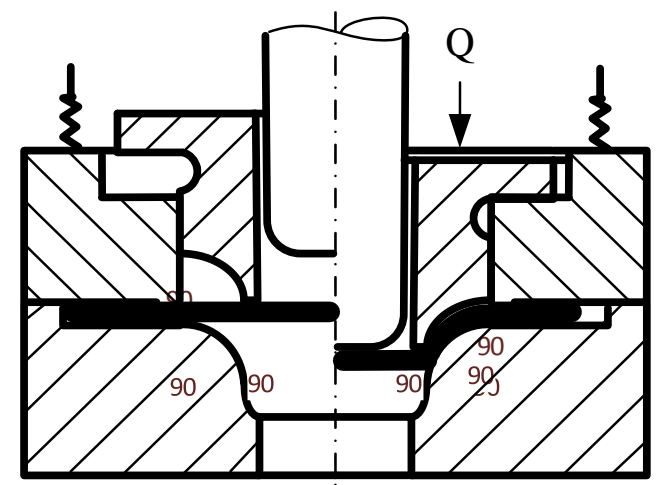

Fig. 20. The combined retaining of the blank 
"Mircea cel Batran" Naval Academy Scientific Bulletin, Volume XX - 2017 - Issue 1 The journal is indexed in: PROQUEST I DOAJ / Crossref / EBSCOhost / INDEX COPERNICUS / DRJI / OAJI I JOURNAL INDEX I I2OR / SCIENCE LIBRARY INDEX / Google Scholar / Academic Keys/ ROAD Open Access I Academic Resources / Scientific Indexing Services / SCIPIO / JIFACTOR

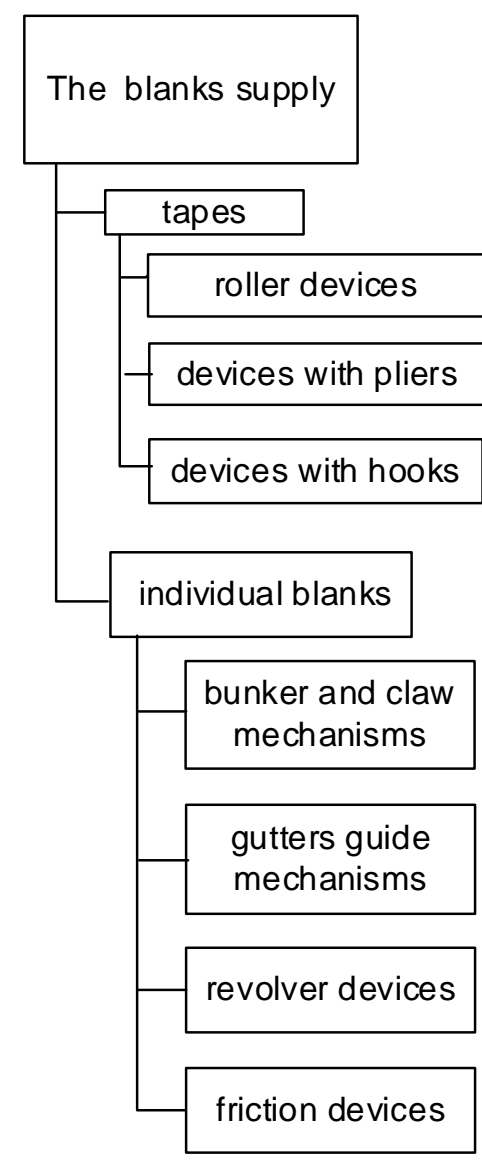

Fig. 22. Subsystem "The blanks supply"

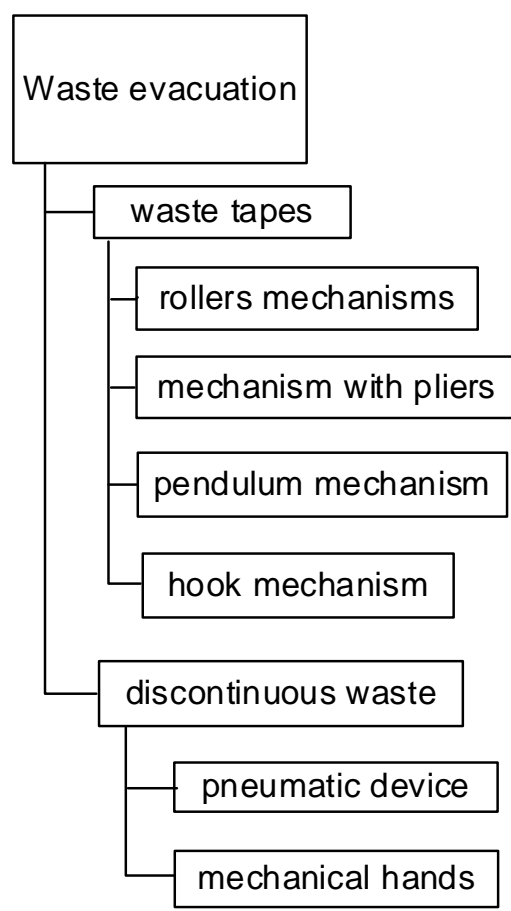

Fig. 24. Subsystem "Waste evacuation"
The punch can be have the rounding radius $r_{p}$ (Fig. 16) or have the shape of a truncated cone (Fig. 17 [2]). The first form of the punch is recommended in case of obtaining small pieces (with a maximum diameter of $80 \mathrm{~mm}$ ), and the second form is used to obtain medium-sized and large parts that require multiple operations.

When not required quality conditions of the piece shallower drawing can be made without restraint (Fig. 18 [5]). If the piece is high, the material will wrinkle. This will straddle the from entering the area of the plate cylinder active and ultimately will rupture the part wall. Obtaining quality parts require the application on a blank of a holding force $(\mathrm{Q})$. If retaining ring rests on the drawing board, then retention is called rigid. It can be flat (Fig. 19 [2]) or combined (Fig. 20 [2]). If the retaining ring rests on blank, then retention is called elastic (Fig. 21 [2]).

The operator leads processing process acting on orders processing system and overseeing its functioning.

The blanks supply subsystem provides bringing the blank in the working position for the start of the deformation process (Fig. 22 [1]).

The piece evacuation subsystem release the die work area making it possible resumption of the processing cycle for a new piece (Fig. 23 [1]).

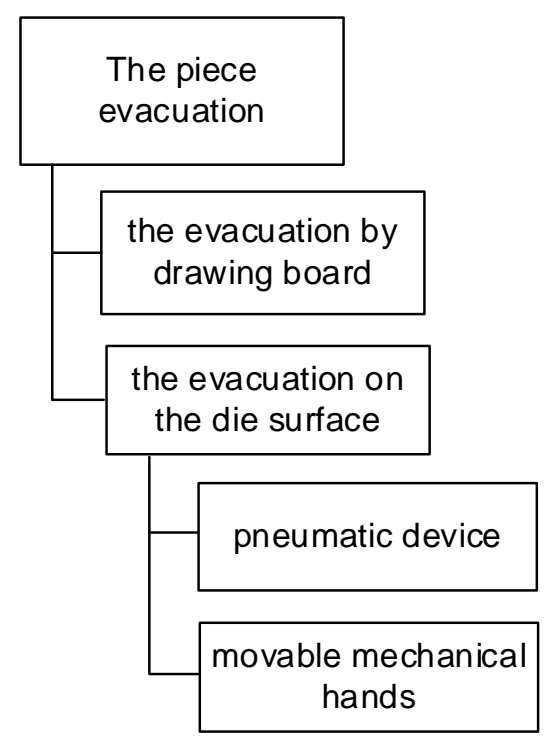

Fig. 23. Subsystem "The piece evacuation" 


\section{"Mircea cel Batran" Naval Academy Scientific Bulletin, Volume XX - 2017 - Issue 1 \\ The journal is indexed in: PROQUEST / DOAJ / Crossref / EBSCOhost / INDEX COPERNICUS / DRJI / OAJI I \\ JOURNAL INDEX I I2OR / SCIENCE LIBRARY INDEX / Google Scholar / Academic Keys/ ROAD Open Access I Academic Resources / Scientific Indexing Services / SCIPIO / JIFACTOR}

The waste evacuation subsystem has similar function with the piece evacuation subsystem (Fig. 24 [1]).

The quality of drawing pieces and other requirements of manufacturing are assured of a good design of the technological process of drawing by choosing the blank, the correct determination of the number of operations, of the sequence, of shape and size of active elements of the die, of how blanks supply, of parts and waste evacuation.

\subsection{The drawing process}

Drawing process can be defined as a set of actions and phenomena that accompany them, leading to obtain drawing parts from flat or hollow blanks. Among the factors that characterize the drawing, the most important are: forces, speeds, deformations, displacements, stresses, friction, drawing grades, degrees of hardening, springback (Figure 25 [1]).

The forces may be: of deformation, of retaining flange blank, of extracting piece on punch,of throwing piece above the plate active, advancement of blank into die.

Forces longer needed for other processing such as notching strip, cropping intervals between two pieces, perforation, shaping and cuts, when they talk about the successive drawing from tape.

The speeds refer mainly to moving speeds of active elements - punching or drawing plates. They are made of working mechanisms of the press and depend on its type. For example, to mechanical presses with eccentric speed is variable and varies from a maximum value when the punch contacts the blank to zero at the end of the working stroke. But at hydraulic presses, the speed is constant in all upon movement of the mold active element..

The movements refer to the blank material during drawing and between drawing. During cupping the blank material concomitantly moving both radially and axially, moving the blank flange to the punch axis to transform the vertical wall of the piece and it moves axially for increasing the height of the wall. Between two successive drawing of the tape, blank moves intermittently for a new drawing.

The tensions arise during the transformation of the blank material in the drawn piece. These are the normal radial tensile stress, which determines the sheeting process of blank flange to punch; tangential normal stresses of compression, which reduces the circumference of the preform flange; flexural normal stresses which occur in the material in its passage over active edges of the plate drawing and punch. In the vertical wall of the piece which takes drawing strength, appear stretching stresses normal, their value is limited by the tensile strength of the material piece. Depending on the reference system to which the tensions, they can be: normal, tangent, principal, equivalent.

The deformations occur during the transformation of the blank material in the concave part by drawing. Thus, in the flange of the blank occurring deformations of compression accompanied by thickening the vertical wall and bottom of the workpiece occurring deformations of stretch accompanied by thinning and in the area of connection of the vertical wall with the flange and the bottom of the workpiece occurring deformations of bending characterized by a thickening on the inside of the curvature and thinning the outside curvature. The willul drawing thinning wall thickness compressive deformations occur accompanied by thinning.

The friction occurs in the process of drawing between the blank surfaces and elements that come into contact during drawing and between which there is relative movement or tendency of relative movement only. To increase the performance of drawing between some of these areas there is concern for reducing friction between the surfaces of the blank and the plate drawing and the element of push of a restraint while among others - between the surfaces of the blank and the punch - the concern of increased friction. Friction reduction is performed using various lubricants and various methods of lubrication.

The degree of drawing results from the comparison part dimensions with those of the blank from which it was obtained - for example the diameter of the cylindrical part workpiece with the blank diameter - or comparing dimensions of the piece - the height of its cylindrical part with its diameter. For different types of parts, materials, relative thickness of the blank and drawing certain conditions were established limit values admissible of the degree of drawing. To values 
"Mircea cel Batran" Naval Academy Scientific Bulletin, Volume XX - 2017 - Issue 1

The journal is indexed in: PROQUEST / DOAJ / Crossref / EBSCOhost / INDEX COPERNICUS I DRJI / OAJI I

JOURNAL INDEX / I2OR / SCIENCE LIBRARY INDEX / Google Scholar / Academic Keys/ ROAD Open Access I Academic Resources / Scientific Indexing Services / SCIPIO / JIFACTOR

equal to or lower the admissible drawing can be achieved in a single operation, while at higher values need more successive drawing.

The degree of hardening characterize the the phenomenon of increase of resistance characteristics and reduction of plasticity after cold plastic deformation of certain materials that are obtained the drawing parts - steel with low or medium carbon aluminum alloys. At drawing parts deep from material hardening middle - steel with low carbon content - requires several successive operations, while the same piece of material hardening strong - steel containing medium carbon - are necessary intermediate operations after one or two drawing operations. The degree of hardening is strongly influenced by the degree of deformation. Since the degree of deformation is greater the greater is hardening. Hardening is a desirable phenomenon on the one hand, and on the other hand undesirable. Materials that do not suffer hardening are incapable for drawing - eg lead. Hardening by cold plastic deformation increases the strength characteristics of the material, so that it is possible to obtain pieces of cheap materials - such as carbon steel - with features comparable to those of pieces from more expensive materials - for example alloy steels. Instead, strong hardening is undesirable because makes it difficult the drawing process.

The elastic recovery is the phenomenon of changing the form of drawn pieces due to the tendency of balancing the tensions that appear in workpiece material during drawing. The elastic recovery is the consequence of one of the basic laws of processing by cold plastic deformation, namely the presence of law elastic strains during plastic deformation. The elastic recovery makes the shape and size of the drawn piece differ from those of the active elements of the die drawing. It is a phenomenon difficult to control powerful influencing negatively dimensional accuracy, shape and relative position of pieces pressed surfaces. The elastic recovery is lower in parts with higher stiffness - eg flanged parts - and higher at parts with lower stiffness.
The drawn piece represent the exiting of drawing process. It strongly influence this process by shape, size, including uniform wall thickness and material to be made (Fig. 26 [1]). 
"Mircea cel Batran" Naval Academy Scientific Bulletin, Volume XX - 2017 - Issue 1 The journal is indexed in: PROQUEST I DOAJ / Crossref / EBSCOhost / INDEX COPERNICUS / DRJI / OAJI I JOURNAL INDEX / I2OR / SCIENCE LIBRARY INDEX / Google Scholar / Academic Keys/ ROAD Open Access I Academic Resources / Scientific Indexing Services / SCIPIO / JIFACTOR

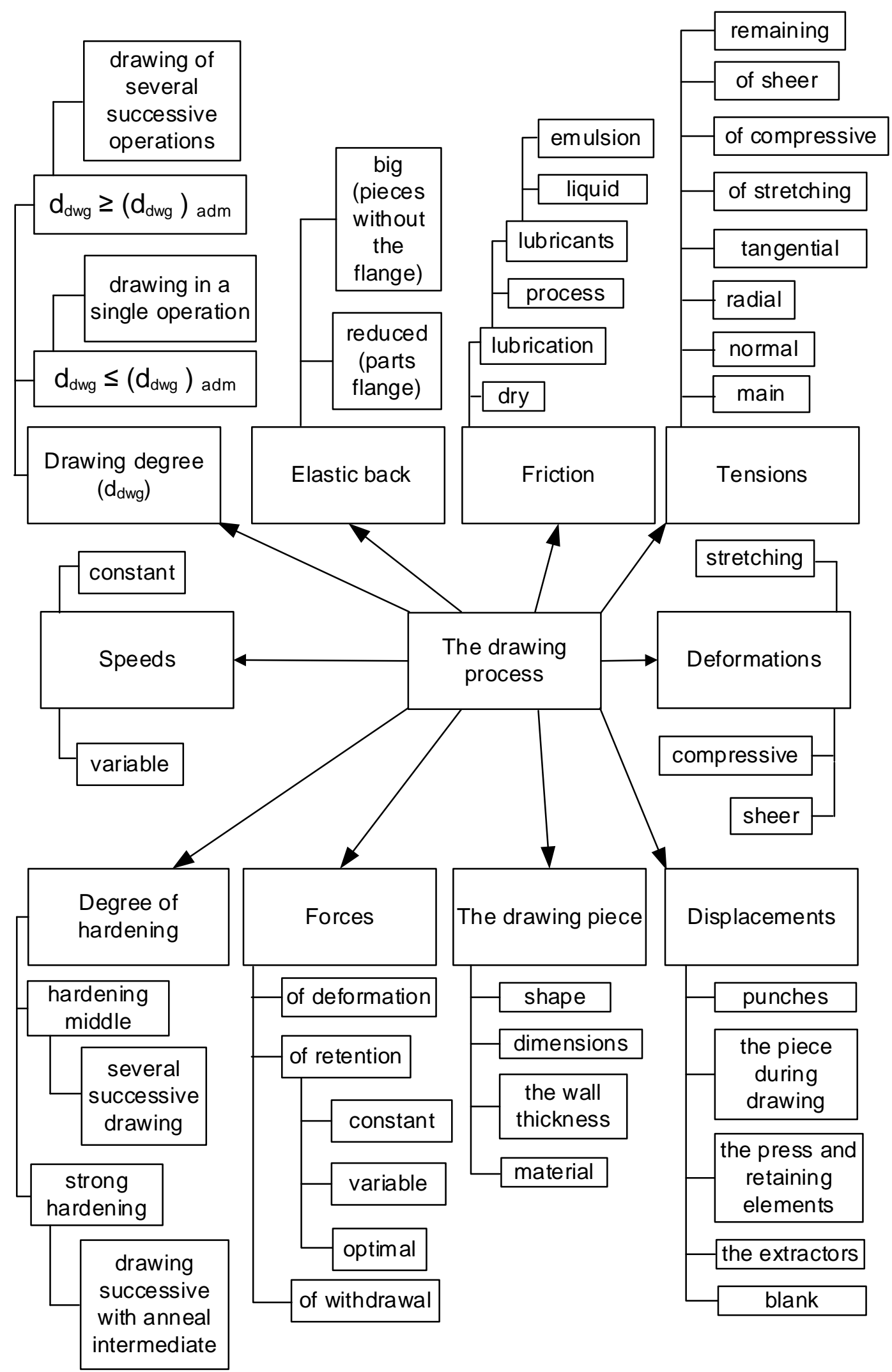

Fig. 25. Factors that make up the drawing process 
"Mircea cel Batran" Naval Academy Scientific Bulletin, Volume XX - 2017 - Issue 1 The journal is indexed in: PROQUEST I DOAJ / Crossref / EBSCOhost / INDEX COPERNICUS / DRJI / OAJI I JOURNAL INDEX I I2OR / SCIENCE LIBRARY INDEX / Google Scholar / Academic Keys/ ROAD Open Access I Academic Resources / Scientific Indexing Services / SCIPIO / JIFACTOR

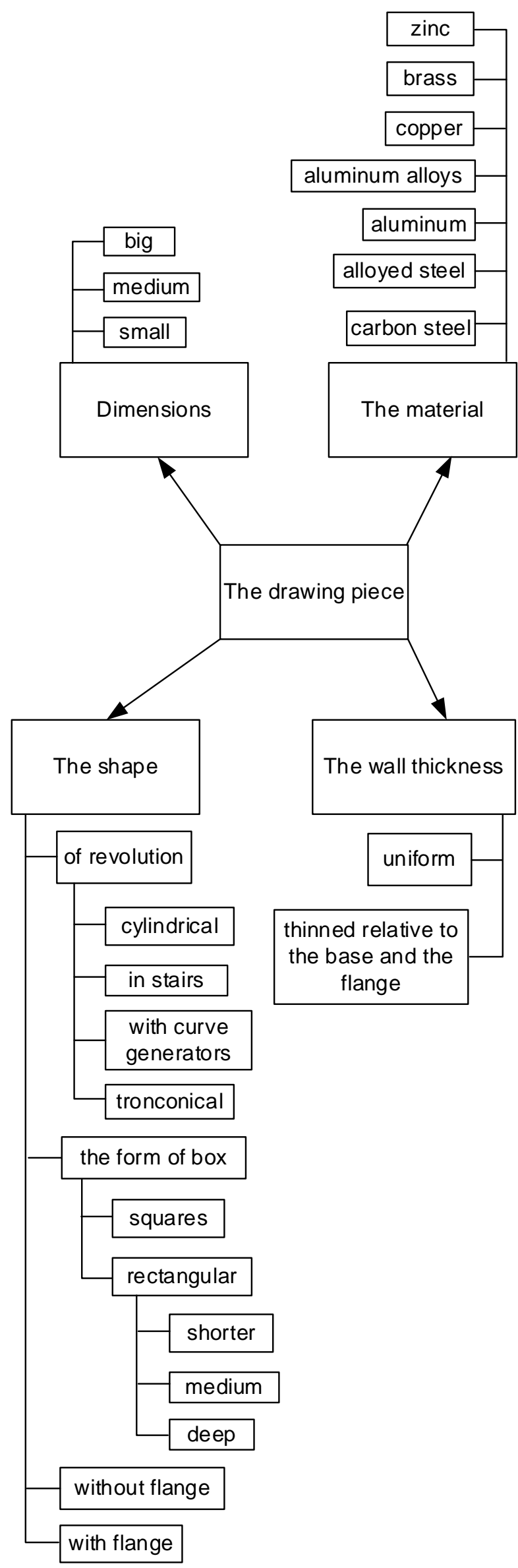

186

Fig. 26 Characteristics of the drawing piece 
"Mircea cel Batran" Naval Academy Scientific Bulletin, Volume XX - 2017 - Issue 1 The journal is indexed in: PROQUEST I DOAJ / Crossref / EBSCOhost / INDEX COPERNICUS / DRJI / OAJI I JOURNAL INDEX I I2OR / SCIENCE LIBRARY INDEX / Google Scholar / Academic Keys/ ROAD Open Access I Academic Resources / Scientific Indexing Services / SCIPIO / JIFACTOR

\section{Conclusion}

The quality of parts pressed and other requirements of manufacturing are assured of a good design of the technological process of drawing by choosing the blank, correct determination of the number of operations, of the sequence of their, shape and size of active elements of the die, of how supply blanks and evacuation parts and waste.

\section{Bibliography}

[1] Iliescu C., Tehnologia presarii la rece , EDP, Bucuresti, 1984

[2] Chioibas A., Cercetari privind influenta conditiilor de deformare asupra calitatii pieselor ambutisate, Bucuresti, 2004

[3] Kiessler H., Fröber H., Materiale destinate deformarii plastic la rece, Werkstattstechnik nr 2, 1971

[4] Teodorescu M., Zgura Gh., Tehnologia presarii la rece, EDP, Bucuresti, 1980

[5] Teodorescu M.,sa, Prelucrari prin deformare plastic la rece, Editura Tehnica, Bucuresti, 1987 